\title{
Potentials and Barriers of Agility in Small and Medi- um Sized Enterprises
}

\author{
Insights from qualitative research in Germany
}

\author{
Joerg Bueechl ${ }^{1}$, Ralf Haerting ${ }^{1}$, Michael Pressl ${ }^{1}$ and Raphael Kaim ${ }^{1}$ \\ ${ }^{1}$ Aalen University, Beethovenstr. 1, 73430 Aalen, Germany.
}

\begin{abstract}
Our explorative, qualitative study uncovers the dynamic processes of agility unleashing or inhibiting potentials within German small and medium sized enterprises through the lens of digitization. Based on an analysis of 22 interviews, we propose a conceptual model, which illuminates antecedents and external determinants of agility and their impact on potentials and performance in organizational settings. In this process we determine digitization both as an external driver and as an internal provider of agility. Resource constraints and traditional leadership styles are SME-specific barriers to agility. How extensively the potentials of agility can be utilized dependents on the moderating factors firm size and department.
\end{abstract}

Keywords: Agile Management, Small and Medium Sized Enterprises, Qualitative Research, Potential and Barriers.

\section{Introduction}

In recent years, markets and industries have been impacted by uncertainty and volatility as a result of digital innovations and disruptions on a global scale. This phenomenon is reflected in the emergence of the by now widely known acronym VUCA, which describes a world characterized by volatility, uncertainty, complexity and ambiguity [1]. An exponentially increasing amount of external economic or environmental disruptions, such as the United States presidential election 2016, the Brexit referendum or just recently Covid-19 forces organizations to cope instantly [2, 3].

Historic data is not necessarily applicable anymore to derive answers to current and future challenges. As a consequence, organizational agility emerged as a widely applied response to guide organizations strategically through these disruptive times to thus ensure their competitiveness. The greater body of research investigates agility in the context of large corporations. However, given the relevance of SMEs as they account for $66 \%$ of the workforce in the European Union [4] and 48\% of the workforce in the USA [5], we want to address this gap by investigating the dynamics of agility in an SME context. Furthermore, there are distinctive characteristics that set SMEs extensively apart from large corporations, not only in quantitative, but also in qualitative terms, which propose promising results when investigating agility in SME contexts [6]. While SMEs appear to be more agile than large corporations [7], they face numerous limitations in the sense of capabilities, resources and external financial access which in turn makes it difficult to conquer organizational inertia along their way towards digital transformation [8, 9]. We consider the investigation of German SMEs, also known as German Mittelstand or Hidden Champions, as particularly promising as they are not only known as the "backbone of the German economy", but also as a leading factor of Germany's overall competitiveness on a broad spectrum [10]. Given the limited amount of extant research on SME's agility in digitization contexts [11], we apply a qualitative research approach, which is well-suited when engaging in inductive theory building [12]. 
Our data collection leads to 22 interviews of employees working in 9 different industries, transcribed on over 170 pages. Based on our data set we developed a model on potentials and barriers of agility in SMEs. Our paper contributes to the literature by identifying the role of digitization both as an external driver and as an internal provider of agility. Other internal drivers in SMEs are consistent with the literature on large companies. The barriers, on the other hand, specifically relate to the context of SMEs in its qualitative and quantitative manifestation and are rooted in resource constraints and traditional leadership structures. The opportunity to exploit the potentials delivered by agility in SMEs is moderated by the department and the firm size.

\section{Theoretical Framework}

\subsection{Agility}

Agility in its various forms, such as strategic agility and organizational agility, is often described as a way to cope with dynamic challenges and thereby not losing one's competitive edge in the VUCA world [13]. The concept of agility dates back to the 1960s and centers primarily around adaptability of the manufacturing industry and its processes [14]. Yet, it was in the 1990s when agility transcended into the business research context to find answers to the eroding competitiveness of the US-American market as a result of production overcapacities. During this time, the term agile described organizations which respond instantly to changing consumer and market expectations with product and process innovations [15]. In the early 2000 s agility has experienced a renaissance with the emergence of agile project management methods, such as SCRUM, KANBAN or Design Sprints, especially in the field of software development [16, 3].

Ever since, an abundance of different approaches and concepts have surfaced in organizational and business research. However, over the course of the last twenty years, there appeared a consensus among scholars that agility serves as an expression of the interdependence and the interplay of sensing and responding abilities [13]. The sensing capability enables an organization to detect environmental change in forms of competitive market opportunities and evolving conditions, whereas the responding capability helps an organization to rapidly seize these sensed opportunities by efficient and effective reactions. [17]. Nevertheless, there is still a need for structuring the heterogenic landscape of agility to receive a holistic understanding of the concept across various disciplines [18].

The VUCA environment, in which companies find themselves, requires companies to sense and obtain a profound understanding of these disruptions in order to derive effective responses to meet market and customer expectations [11]. Information systems as a key prerequisite for data management are fundamental enablers for companies to match changing external conditions with internal resources and capabilities to successfully navigate through the challenges which have been imposed by the disruptive environment. In this context the situation around the COVID-19 pandemic may foster a mindset in which learning from change is leading into an era of agility, as Batra (2020) notices [21]. Contemporary agility research however often centers around the information system context, particularly around software development, as agility is often regarded both a key prerequisite as well as a consequence of digitization [19]. In this vein, Sambamurthy et al. (2003) argue that investments in IT competence enhances an organization's agility, digital options and entrepreneurial alertness, thus allowing competitive actions and improving financial performance [20]. In a next step, Leonhardt et al. (2016) distinguish between entrepreneurial and adaptive agility and investigate the positive influence of IT on these two constructs. Entrepreneurial agility aims at proactively sensing environmental changes and responding with the development of customized processes, services or products, while entrepreneurial agility takes a reactive approach and focuses on keeping pace with anticipated and upcoming innovations [22].

Although agility can have a positive impact on company performance, there is an ongoing controversy on whether or not it has an exclusively beneficial effect [13]. In this vein, a 
lack of either element (sensing or responding) can lead to an impaired equilibrium which again results in a damaging effect on the organization and its performance [17]. While some authors call for unconditional agility and radical transformation, others take a more cautious approach and warn about costs and efficiency to be sacrificed for the sake of agility [23]. An increasing number of scholars are dedicated to resolve this quandary by introducing the concept of organizational ambidexterity. Ambidexterity refers to an organization's ability to efficiently manage current processes and business fields by exploiting existing competencies, while proactively exploring new opportunities by addressing constantly changing demands of the future at the same time [24]. These opposing pairs of concepts, namely exploring vs. exploiting and respectively sensing vs. responding, are highly interdependent in their nature. While the exploitation component mainly comprises scaling daily business activities and therefore represents the continuity-based end of the ambidextrous spectrum, the exploration component encompasses both elements sensing and responding and thus represents the disruptive and agile-based end of the spectrum. Agility can therefore be regarded as a dynamic capability for resolving the ambidextrous quandary [25, 24].

\subsection{Agility among Small and Medium Sized Enterprises (SMEs)}

The concept of agility and ambidexterity evolved from an idea to a complete area of research over the past 20 years: Overall 135 articles have been published in this domain in the year 2000, while in 2011 already nearly 600 articles have been published on this topic. This number continued to increase steadily, and last year a total of 1546 articles dealing with agility or ambidexterity have been published. However, only very few of these publications address SMEs and even less go beyond investigating agility in the software development context. Nonetheless, agility is not only a relevant concept for large corporations and IT related companies, but for SMEs across different industries as well. It is particularly the ongoing debate of whether or not SMEs are more agile than large corporations which requires further research. Compared to large corporations, SMEs are lean, more informal and less hierarchically structured, which are important features of an agile way of working [11]. Furthermore, in order to compensate for their lower degree of leverage due to their size, SMEs often heavily invest in building external relationship networks, which help them to tap on new opportunities together with other partners [27, 28, 29]. On the other hand, the limitation of resources which SMEs are confined to, such as financial and human resources as well as the capability to transform rigid processes into agile ones, are key liabilities of SMEs on their way to agility [11, 30]. Despite that, in order to ensure long-term success, every mediumsized enterprise and family business need to facilitate exploration and exploitation [31]. As a consequence, more research is needed to shed light on the context of agility in SME contexts.

From a cultural perspective, there exists only sporadic research on agility and ambidexterity that examine German companies. The majority of research investigates the cultural contexts such as USA and China [25, 32, 33, 34, 35, 34, 35]. We chose Germany as the country of investigation for various practical and conceptual reasons. German SMEs are of great significance as they account for $99.6 \%$ of all companies in Germany and for $58.5 \%$ of the German workforce [38]. Furthermore, Germany is known for the success stories of Hidden Champions, a specific subgroup of SMEs which are highly specialized world-market leaders shaped by international dominance in various product niches [10, 39]. Moreover, in German SMEs ownership, management and liability are typically interdependent. From a demographic perspective, in 2016 more than one third of all company owners were at least 55 years old [40]. This phenomenon goes along with a traditional, hierarchical style of leadership, which commonly is opposed to environments, in which agile mindsets can thrive as top-down communication and excessive control leaves no space for flexibility [23]. Next, Germany conceptually represents a risk avoidant culture, scoring relatively high on Hofstede's uncertainty avoidance scale [41]. As uncertainty avoidance goes along with tolerance for ambiguity, a beneficial factor for agility [40], Germany can be seen as culturally disadvantaged in terms of agile management. Lastly, Germany is worth investigating regarding its world share in GDP as well as its extensive trade activities [43]. 
The aim of our study is to examine specific boundary conditions, challenges, and benefits of organizational agility as a result of digitization for SMEs in Germany. Previous research calls for more studies to unveil boundary conditions on the restrictions and limitations of agility, namely to assess at which point the benefits of exploration endeavors outweigh the associated costs [26]. Second, the question of whether it is preferable to develop selective agile processes that are critical for organizational success or to develop a holistic agile landscape across the organization and its functions instead, also needs to be answered [13]. Moreover, Leonhard (2017) calls for more research to unveil the natural boundary of agile transformation, namely to identify the point including its boundary conditions at which organizational agility reaches its limit and cannot be enhanced anymore [32]. In order to address the aforementioned calls for future research and research gaps, we deduced following research question, which we try to find answers on with the help of our qualitative data:

\section{What are the opportunities and barriers of agility among SMEs?}

\section{Methodology}

\subsection{Research Design}

As the assessment of opportunities and barriers of agility on SMEs in a cross-cultural setting is still a nascent research area, lacking established theory, we regard an inductive and explorative research design as suitable. Such a research approach is appropriate when investigating dynamic and complex phenomena and engaging in inductive theory building [12] in form of mid-range theory [44]. Our research design comprises 22 in-depth, semistructure interviews, which provide a more profound understanding of the overall dynamics than quantitative research, which applies a more deductive approach [45].

\subsection{Research Setting}

To ensure comparability of the data collected, we conducted all interviews in a single country for the above-mentioned reasons. We have further selected SMEs which account for 50-1000 employees [46]. Furthermore, we focused on organizations in the production sector, as service, software or IS companies in many cases already employ agility techniques and methods. We also consider agility in German SMEs worthwhile investigating due the high degree of trade activities of Germany resulting in extensive internationalization endeavors and growing complexity [3]. In order to guarantee ecological validity [47] and to obtain a holistic understanding of the dynamic processes under investigation, we interviewed individuals on a broad spectrum, working in different functions and different industries [48]. Our interviewees were individuals who are exposed to agility, ambidexterity and/or other topics relevant for this study in scope of their work. This approach ensures comparability across functions and companies to tease out individual phenomena and their specific context.

\subsection{Data Collection}

The data set of the research project consists of 22 semi-structured interviews conducted 2019 and 2020 in 20 different departments from twelve different organizations in nine different industries, with an emphasis on the manufacturing sector. Participants from as many different functional areas and hierarchical levels as possible were to be interviewed in order to obtain a broad view of the situation and to minimize the potential for bias of a single individual. $60 \%$ of the interviewees are in management positions. A total of almost 13 hours of interview material was recorded and transcribed to over 170 pages. A list of the individual interview partners can be found in table 1. Semi-structured interviews guarantee a reasonable degree of consistency in the questions and thus establish comparability between the interviews without preventing the discovery of unknown and unexpected phenomena [49]. We opted for a narrative interview design which helped us to collect rich data from people in various roles and situations [49] to access interviewees' motivations and thoughts. 
Table 1. Overview of Interviewees

\begin{tabular}{|c|c|c|c|c|c|}
\hline Firm & Interviewee & Gender & $\begin{array}{l}\text { Department/ } \\
\text { Position }\end{array}$ & Industry & Employees \\
\hline 1 & Data 1 & female & $\begin{array}{l}\text { Human Re- } \\
\text { sources }\end{array}$ & Telecom Services & 75 \\
\hline 2 & Data 2 & female & $\begin{array}{l}\text { Project Man- } \\
\text { agement }\end{array}$ & Data/Media & 320 \\
\hline 3 & Electro 1 & male & $\begin{array}{l}\text { Head of Logis- } \\
\text { tics }\end{array}$ & Electrical Industry & 350 \\
\hline 3 & Electro 2 & male & $\begin{array}{l}\text { Product Man- } \\
\text { agement }\end{array}$ & Electrical Industry & 350 \\
\hline 3 & Electro 3 & male & $\begin{array}{l}\text { IT-Project } \\
\text { Management }\end{array}$ & Electrical Industry & 350 \\
\hline 4 & Food 1 & male & $\begin{array}{l}\text { Head of Logis- } \\
\text { tics }\end{array}$ & Food Production & 900 \\
\hline 5 & Food 2 & female & $\begin{array}{l}\text { Head of Pro- } \\
\text { duction }\end{array}$ & Food Production & 140 \\
\hline 5 & Food 3 & male & CEO & Food Production & 140 \\
\hline 5 & Food 4 & female & $\begin{array}{l}\text { Head of Logis- } \\
\text { tics }\end{array}$ & Food Production & 140 \\
\hline 6 & Machine 1 & male & CEO & Mechanical Engineering & 270 \\
\hline 7 & Machine 2 & male & $\begin{array}{l}\text { Head of Pro- } \\
\text { duction }\end{array}$ & Mechanical Engineering & 600 \\
\hline 7 & Machine 3 & male & Production & Mechanical Engineering & 600 \\
\hline 7 & Machine 4 & male & Production & Mechanical Engineering & 600 \\
\hline 7 & Machine 5 & male & Logistics & Mechanical Engineering & 600 \\
\hline 8 & Textile 1 & female & Head of HR & Textile Industry & 800 \\
\hline 9 & Textile 2 & male & Finance/Sales & Textile Industry & 650 \\
\hline 10 & Tool 1 & male & $\mathrm{HR}$ & Tool Manufacturing & 530 \\
\hline 11 & Trade 1 & male & Head of IT & Production/Mail Order & 800 \\
\hline 12 & Trade 2 & female & Head of HR & Paper Industry/Mail Order & 270 \\
\hline 12 & Trade 3 & male & CEO & Paper Industry/Mail Order & 270 \\
\hline 12 & Trade 4 & male & Head of Sales & Paper Industry/Mail Order & 270 \\
\hline 12 & Trade 5 & male & CFO & Paper Industry/Mail Order & 270 \\
\hline
\end{tabular}

The interview guide had three sections. The first part dealt with basic information about the interviewee such as demographics, tenure, duration of the current position, current tasks, the company's industry or company culture. The second and main part of the questionnaire dealt with agility in the company. Questions covered topics such as experiences with agility, initial successes or problems and the connection to digitization and management style. The questions were first asked very openly to reduce biases. In the further course, probes were used in a more specific way to learn about specific examples and descriptions of relevant situations. In order not to disrupt the interview flow, the sequence of the questions was held in a flexible manner. At the end of the interview the interviewees were given the opportunity to reflect on issues which they considered to be relevant, but which have yet remained unaddressed. The interviewees were also given the opportunity to emphasize any open aspects or issue of their choice. An interview lasted on average 35 minutes, was digitally recorded and then transcribed verbatim in the original language German. We stopped conducting interviewing once we reached the point of data saturation, the point when no information emerged [50]. 


\subsection{Analysis}

The data was analysed using the Grounded Theory [51]. Therefore, first open coding, then axial coding and lastly selective coding was applied. In the open coding phase, all material was read and basic, general codes were assigned. These codes can originate either from the direct formulation of the interviews or from constant comparison with the literature. In a next step, the resulting large number of codes were then grouped into categories to transition from a descriptive to a conceptual level using the constant comparative method [51]. We have constantly compared and juxtaposed different parts within and across interviews to ensure consistency. In this way connections between our coded appeared and categories could be formed. For example, the codes "Digital Technologies" and "Data Security" have been merged into first order category "Digitization", and then combined with the first order category "Increasing Speed" into the higher order category "External Driving Factors of Agility". In order to retrace our method, we provide an overview of exemplary codes and categories in figure 1 . The quotes related to the exemplary codes are integrated in the results section.

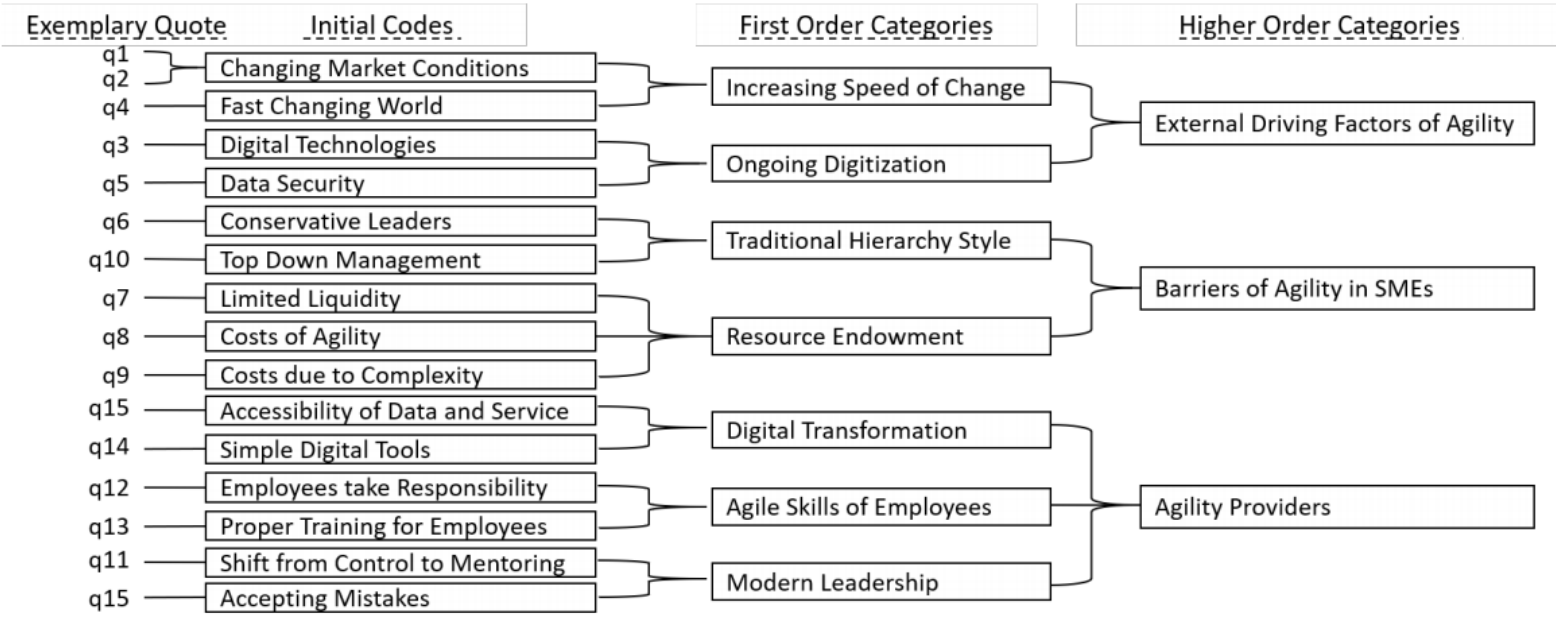

Fig. 1. Exemplary Procedure of the Data Analysis.

Subsequently, in the selective coding phase, the relationships and connections between the categories have been analysed, summarized and visualized in figure 2.

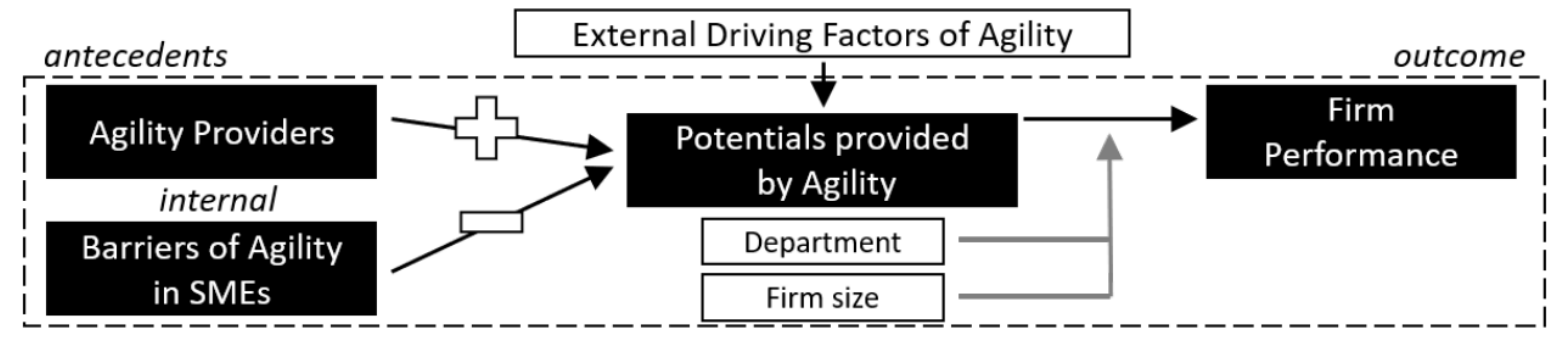

Fig. 2. Model of Potentials and Barriers of Agility in SMEs.

During the analysis, theoretical memos were written, which helped to cycle back and forth between literature and collected data to ensure validity. The data analysis was mainly carried out by the first author and the interim results and findings were regularly discussed intensively with the other authors. The transcribed interviews were analysed using the software for qualitative research MAXQDA.

\section{$4 \quad$ Empirical Findings and Model Conceptualization}

Based on our data we will introduce our findings, juxtapose these with existing research, and ultimately derive a comprehensive model which represents the process of agility facilitation and aligning it with firm performance. This chapter is organized according to the different 
categories which emerged from the analysis of our data-set. First, we will begin by introducing the external driving factors of agility, followed by the internal antecedents of agility, namely facilitating agility providers and inhibiting barriers of agility among SMEs. Second, the resulting potentials delivered or provided by agility are presented, and third, agility-induced potentials, including moderating factors.

\subsection{External Driving Factors of Agility}

Digitization has proven to be a key driver to impact social and economic life as it helps to increase efficiency with the help of information technologies, particularly in the areas of production, administration and ext. communication. As a result, digitization and its implementation lead to disruptive changes in both - internal and external processes - which organizations need to flexibly adapt to. The interviewed experts mentioned numerous times how digitization-induced disruptive environments perpetually forces them to quickly adapt to these changes to retain their competitiveness. Electro 2 (q1) and Media 2 (q2) emphasized that changing market conditions forces organizations to be agile to respond faster and more flexibly to customer needs.

Furthermore, digital transformation processes differ extensively from traditional forms of strategic change. Interviewee Electro 2 (q3), a product manager for electrical components, concluded that digital technologies have accelerated the speed and shape in which enterprises compete with one another. Furthermore, agile working environments even impact the way in which companies create value and interact with their customers and partners [52]. In this fast-evolving context it has become vital to respond quickly to new situations and agility has emerged as a promising approach in mastering the rising degree in complexity. In a similar vein, as interviewee Trade 1 (q4) stated: The world is changing faster and faster and I can only deal with a fast change by working in an agile way. Another example for fast-paced changing opportunities, which agility offers is being raised by Trade 2. The HR Business Partner of a paper wholesaler claimed that the market and especially the sector they are doing business in is declining. Therefore, the interviewee sees the ability to adapt quickly and flexibly as one key to identify opportunities to diversify the company portfolio and to build up new pillars for the enterprise. His colleague Trade 4, who works in the sales department, concurs completely. Only those enterprises which are open to new ventures in this disruptive market are able to act successfully in the future.

There are also external factors which impede agility and limit a transformation as described above. Externally imposed norms and regulations inhibit quick and efficient execution of the jobs to be done. Interviewee Data 1, responsible for connecting cities to fibreglass lines, emphasized the relevance of strict regulations when executing roadworks. He outlined the constraints associated with complying with the mandatory construction steps. Opportunities for efficiency improvements are therefore strictly limited due to public regulations.

\subsection{Agility Providers}

After providing external driving factors, this section focuses on internal antecedents. The analysis has identified three basic types of agility providers: leaders, employees and digital transformation. For employees to be empowered to assume responsibility within agile and self-organized teams [16], in a first step it requires the management to abandon the mindset of an overall controlling instance. As the product manager Electro 2 (q15) mentioned, a leader in charge should abandon parts of his responsibility, accept mistakes and empower employees to act self-organized and independently. CEO Machine 1 added that this inner shift takes a lot of effort, time and patience to live up to these expectations. Also Trade 1 (q11) stated that this can be understood as an ongoing process for leaders and goes along with a transition in leadership style shifting from control to mentoring and coaching.

At the same time the organization relies on the employees' willingness to take an active part by taking over responsibility as the HR Business Partner Data 1 (q12) emphasized. But according to Project Manager Data 2 (q13), it is the company that is required to educate 
employees in how to use agile working methods. The Head of IT continued that a central provider of agility is empowering employees to achieve the common goal in their own way. To unlock the full potential within the exchange between leaders and employees, transparency and open communication is key according to Trade 1. Data 1 further concluded that all employees, who are involved in the process, must be aware of the expected targets as well as possible challenges in order to succeed together in a creative way.

Interviewee Machine 1 stated that the processes and agile methods must be tailored to the specific context of the organization, or the organization needs to adapt own techniques. Either way - to design a perfect fit between the organization, the business model and the employees, transparent communication is needed. To achieve a sustainable shift in working behavior the capabilities for reconfiguration and process concurrency are further vital elements. One key provider thereof is once again digitization. Agile working methods often amplify the requirements for digitized processes and support the overall digital transformation. As Trade 3 and Trade 5 stressed, enhancing process speed is a key argument in favor of striving for a higher degree of agility. Interviewee Textile 1 (q14) considers the simplification in sophisticated digital tools as a major milestone. In this regard, Textile 2 (q15), who works in sales and finance, sees the main impact in the accessibility of services during mobile working. The opportunity of a flexible and agile working environment, sustained by digital technologies, is generally appreciated by several interviewees.

The identified agility providers are also proposed as the agility enablers of Conforto et al. (2014) as leaders show similar features to the described organization category, collaborators to project team category and digital transformation to the process category [53].

\subsection{Barriers of Agility in SMEs}

Besides the providers that enable agility in SMEs, there are also barriers that inhibit agility. Leaders and employees are agility providers, but in some cases, they can also be the barriers of agility in SMEs. Especially leaders that exert control can impede agility. Expert Electro 1 (q6) stated: Especially as far as managers are concerned, there are still some really oldfashioned conservatives who dictate everything. This attitude is difficult to reconcile with an agile way of working. Especially when it comes to the extraordinary situation of SMEs based in Germany, the resource endowment is worth to be taken a further look at [54]. As described above, in many German SMEs the ownership and management responsibility are integrated in the same person or circle of persons and SMEs are often externally financed by bank loans and equity capital. Expert Food 3 (q7) emphasized in this context the limited availability of liquidity compared to large corporations. In this regard, Machine 4 (q8) urged not to forget about time and resources needed to implement agile working methods like SCRUM and Kanban in the first place, especially as SMEs deal with fixed lead times which again restricts process flexibility. Expert Food 1 (q9) pointed out that a key challenge to respond to increasing complexity is represented by resource limitations, which makes it more difficult to compete with larger corporations.

As already mentioned, hierarchy is often regarded as one of the biggest obstacles when implementing agile working mindsets. Most interviewees also reported in this respect that their SMEs are shaped by a flat hierarchical landscape as well as by supportive and appreciative working relationships. However, a closer analysis of the management and communication style revealed discrepancies. Data 2 stated for example We work collegially together, but we still have the hierarchies with the boss and you don't call him by his first name. Also, Tool 1 (q10) says it's very collegial, we also have rather few hierarchical levels, while at the same time he says about the management style: Since l've been here at the company [2 years] it's top down.

This classical hierarchy often depends on the leadership style of the owner. With regards to agility, the relationship between managers and employees is an essential contextual factor. Agile working methods can only be successfully implemented if managers understand leadership not as a means of control, but as a concept which facilitates a coaching process 
based on a mutual trusting relationship [55]. But even a change of management does not imply immediate change and may create additional barriers. As expert Textile 1 stated, the transition process, which is induced by a manager and directed at the shift from a strictly owner-driven enterprise to a more open one, takes a significant amount of time. Although the employees are encouraged to take responsibility, it takes time to open up into the new cooperative ways of working. Often the attempt to achieve more organizational agility fails because of organizational inertia. In this vein, a mature organization tends to continue on its current trajectory [13]. The CFO Trade 5 (q26) emphasizes an intense conflict between the two extreme positions never change a running system and a completely agile working methodology. Especially in SMEs, the mentality of the ever-lasting principles and the resistance to give up strictly structured methodologies tends to stick with the former position.

\subsection{Potentials provided by Agility}

A variety of potentials which agility provides could be derived from the data. The examples can be divided into the following categories responsiveness, speed, flexibility and competency [56]. With the help of agility, companies can involve the customer in the development process of new products. As Expert Machine 1 (q16) pointed out, customer feedback can be implemented at a faster rate. He explained this by an agile product development process, which the company he works for is currently establishing: It is different in the agile environment, because at the beginning we bring techniques like design thinking into the process, where we try out what the customer needs, what kind of problems he actually has, and how can we solve them. As a consequence, this leads to improved responsiveness. In addition, agility offers the fundamental potential to act and respond faster. Trade 1 (q17) mainly strives for agility to increase speed. Machine 3 (q18) emphasized: You're able to reduce complexity in modern production facilities which improves the process speed enormously. Being agile enables organizations to be flexible in uncertain times. Machine 1 (q19) pointed out: I need agility when I do not know exactly what I should or can or must do the day after tomorrow. [...] That means I have to be flexible. Further potentials provided by agility can be clustered in the category competencies. One of them represents increased inspiration and creativity when seeking and including employees' opinions and feedback. This is a means to improve team spirit and intrinsic motivation as Textile 1, Food 4 and Textile 2 stated. According to Data 2, agility also creates transparency and thus helps to understand and set a common goal in a project. Machine 1 (q23) concludes that agility helps to optimize processes to resolve what he calls monster processes.

\subsection{Moderating factors}

Additional factors were identified which influence the ability to exploit the potential of agility described above. The task orientation of the department in which agility is used and the firm size in general moderate the influence of the firm's potential on its performance. The analysis of the data provided evidence that some departments are suited for agility processes while in other departments an agile way of working is impeding the working progress. The IT department was mentioned by numerous interviewees like Machine 1 and Electro 3 as a department where agility adds value. Further, in project management, research and development and strategic driven fields, there exists a basis for agility facilitation. Sales and marketing were also emphasized, as the opportunities of executing creative and customized ways of working were highly valued by experts Data 1 and Food 1 . Also, logistical functions need to adopt agile working methods, not to endanger the supply chain performance as stated by Machine 5 (q20). In contrast, Trade 4 (q23) pointed out, there are some departments in which the adoption of agility does not achieve the expected potential. Especially operations and administrative functions, which are shaped by continuity-based routines, need to function reliably in an efficiently and effective manner, and therefore leave little for creativity and flexibility [23]. Or as Trade 2 (q24) stated it out: Once a process is defined and running the going concern continuity is competing with agility and must be weigh up with each other. Further, departments, such as accounting or controlling are bound by a multitude of norms and regulations. Experts therefore underlined efficiency losses rather than improved company perfor- 
mance attributed to agile working methods. Production was also frequently mentioned as an area, where the implementation of agility does not attribute to an added value. This was rather surprising, as agile manufacturing or production is widely accepted and implemented, but apparently in the German research context only to a limited degree.

A further aspect with regards to departments as a moderating factor is the workingrelationship between agile and non-agile working teams within organizations. As the experts summarized, digital transformation simplifies the interaction, but the interface still needs to be monitored very closely. A mutual comprehension as the CEO Food 3 (q21) called it, needs to be established as a foundation, although friction losses can occur. Trade 1 (q22) mentioned that in line with their transformation process it was crucial to completely shift project related work towards agile two-week iterative planning processes. In their experience it was necessary to align the entire value-chain to the new methodology. Otherwise, project steps would not have been met. However, a challenge emerges in inter-team collaborations in form of bottlenecks if agile teams fail to deliver as the descriptions of Data 1 indicate.

The other factor which moderates the influence of the potentials on firm performance, is the firm size itself. According to many experts, small companies close up to 50 employees are more applying agile methodologies as for their size. The underlying reason is that in small companies, every employee tends to flexibly fill gaps and acts on a day-to-day basis without consciously dealing with the construct agility itself. In SMEs, a standardized process landscape is often missing, as the Head of HR Textile 1 (q24) described, while larger corporations' function less efficient as for their cumbersome structures. The decision-making processes in larger organizations often is more time consuming and reaction speed also suffers along with growing hierarchy, as Machine 3 (q23) added. Therefore, especially large companies, which are commonly impeded by organizational inertia, can capitalize on the assets of agility. We therefore propose that firm size might positively moderate the influence of potentials provided by agility on firm performance.

\section{Discussion}

Based on the analysis of the empirical qualitative data we collected on agility in German SMEs, we developed a conceptual model, which is depicted in Figure 2. Both, similarities and differences between SMEs and larger organizations were identified. Both company types share similarities in the field of agility providers as well as with regards to potentials provided by agility, which concurs with previous research [51, 53]. In contrast, the barriers of agility appear to be specific to the SME context. These specific barriers can be mainly attributed to the above-mentioned resource constraints of SMEs, along with hierarchical structures and traditional leadership styles, which appear to be a German cultural phenomenon. Therefore, we see great value in agility research in SME contexts, also from a cultural perspective.

Despite these barriers, it was evident that German SMEs already demonstrate agile working practices in many cases. The examined service companies are already considerably further advanced in this respect than those companies with a manufacturing background, which might not be overly surprising. However, they often do so in an unstructured and even unconscious way, without explicit associations with agility. SMEs in many cases are therefore less methodologically agile than larger companies, which results in a call for action.

\subsection{Implications for Practice}

Our model helps SME managers to facilitate the process of agile transformation by utilizing their limited resources in a more targeted and thus more efficient way. During this process our model will reveal how many factors constitute an agile mindset and which steps need to be taken: First, managers need to differentiate internal agility providers as well as barriers. By juxtaposing these factors, managers can identify specific potentials of agility. Our study shows that agility is not a concept to be applied in every context, namely in all departments and business functions. However, if SME managers identify suitable departments and busi- 
ness functions, they will succeed by being able to implement agility in a targeted and customized way. Furthermore, it is helpful for managers to be aware that they may encounter many internal barriers in such a transformation process. They need to understand that the involvement and empowerment of employees is key, which again often requires a reassessment of a leader's own leadership style.

\subsection{Implications for Research}

Our paper aims to integrate the key findings based on the conceptual model of agility of Sharifi and Zhang (1999) into an SME context [53]. By doing so, we provide boundary conditions for the application of agility in SME contexts. Specifically, our paper provides deeper insights into the agility providers and external factors driving agility as well as regarding barriers of agility. Additionally, our study indicates that cultural context impacts the benefits and challenges of agility on firm performance as well. In future studies, we propose to investigate in more detail the extent to which the concept of ambidexterity provides a possible solution to bridge the gap between agile and non-agile departments and business units.

Nonetheless, we acknowledge the limitations of our study. First of all, our results stem from qualitative empirical research and thus need to be validated by quantitative studies. Furthermore, our cross-sectional study would profit from a longitudinal study to tease out the dynamics associated with antecedents and consequences of agility in a SME context. Furthermore, our study highlights that particularly barriers of SMEs provide promising avenues for further research as they are clearly distinct from the barriers that apply to a larger corporation context. Last, the terms agility and ambidexterity are largely unknown in German SME's beyond IT business function. Therefore, agile working approaches in our targeted companies were rather tacit. Despite these limitations, we are confident that our research adds value to theory development in the fields of agility and SMEs in specific cultural settings.

Acknowledgement: This work is based on several projects and theses at Aalen University. We would like to especially thank Christiane Weiler, Markus Buck, Nils Urban and Christian Neldert who contributed within a project in master class. Also, Diana Schmidt and Alexander Schmidt supported with her raw data generation collection for their Master respective Bachelor theses. We would like to thank all contributors for their great support.

\section{References}

[1] Bennett N, Lemoine J. What vuca really means for you. Harvard Business Review, 2014.

[2] Economic Policy Uncertainty Index. Global economic policy uncertainty index. http://www.policyuncertainty.com/global_monthly.html. Accessed 2021 May 5.

[3] Kaim R, Härting RC, Reichstein C. Benefits of Agile Project Management in an Environment of Increasing Complexity-A Transaction Cost Analysis. Smart Innovation, Systems and Technologies, vol 143. Intelligent Decision Technologies 2019. 2019 Jun. https://doi.org/https://doi.org/10.1007/978-981-13-8303-8_17

[4] Dyfed L. Viele Kleinstunternehmen in der EU.

https://de.statista.com/infografik/9755/unternehmenslandschaft-in-der-eu/. Accessed 2020 July 10 .

[5] United States Census Bureau. Business Dynamics Statistics. https://www.census.gov/programs-surveys/bds.html. Accessed 2014.

[6] The Leader. In: Hidden Champions of the Twenty-First Century.. New York, NY: Springer; 2009. https://doi.org/https://doi.org/10.1007/978-0-387-98147-5_10

[7] Dibrell C, Davis PS, Craig J. Fueling Innovation through Information Technology in SMEs. Journal of Small Business Management. 2008 04;46(2):203-218.

https://doi.org/10.1111/j.1540-627x.2008.00240.x 
[8] Li L, Su F, Zhang W, Mao J. Digital transformation by SME entrepreneurs: A capability perspective. Information Systems Journal. 201706 20;28(6):1129-1157.

https://doi.org/10.1111/isj.12153

[9] Argote L, Ingram P. Knowledge Transfer: A Basis for Competitive Advantage in Firms. Organizational Behavior and Human Decision Processes. 2000 05;82(1):150-169. https://doi.org/10.1006/obhd.2000.2893

[10] Audretsch DB, Lehmann EE, Schenkenhofer J. Internationalization strategies of hidden champions: lessons from Germany. Multinational Business Review. 201804 16;26(1):2-24. https://doi.org/10.1108/mbr-01-2018-0006

[11] Chan CM, Teoh SY, Yeow A, Pan G. Agility in responding to disruptive digital innovation: Case study of an SME. Information Systems Journal. 201808 09;29(2):436-455.

https://doi.org/10.1111/isj.12215

[12] Eriksson P, Kovalainen A. Qualitative Methods in Business Research . Second Edition. 2015.

[13] Tallon PP, Queiroz M, Coltman T, Sharma R. Information technology and the search for organizational agility: A systematic review with future research possibilities. The Journal of Strategic Information Systems. 2019 06;28(2):218-237.

https://doi.org/10.1016/j.jsis.2018.12.002

[14] Burns T, Stalker M. The management of innovation. London: Tavistock Publications; 1961.

[15] Nagel RN. 21ST Century Manufacturing Enterprise Strategy Report. Defense Technical Information Center; 1992 01. https://doi.org/10.21236/ada257032

[16] Manifesto for Agile Software Development. https://agilemanifesto.org/. Accessed 2001.

[17] Overby E, Bharadwaj A, Sambamurthy V. Enterprise agility and the enabling role of information technology. European Journal of Information Systems. 2006 04;15(2):120-131. https://doi.org/10.1057/palgrave.ejis.3000600

[18] Conboy K. Agility from First Principles: Reconstructing the Concept of Agility in Information Systems Development. Information Systems Research. 2009 09;20(3):329-354. https://doi.org/10.1287/isre.1090.0236

[19] Batra D. The Impact of the COVID-19 on Organizational and Information Systems Agility. Information Systems Management. 2020 Oct 01;37(4):361-365.

https://doi.org/10.1080/10580530.2020.1821843

[20] Lindner D, Leyh C. Organizations in Transformation: Agility as Consequence or Prerequisite of Digitization?. Business Information Systems. Lecture Notes in Business Information Processing, vol 320. BIS 2018.. https://doi.org/https://doi.org/10.1007/978-3-319-93931-5_7

[21] Sambamurthy, Bharadwaj, Grover. Shaping Agility through Digital Options: Reconceptualizing the Role of Information Technology in Contemporary Firms. MIS Quarterly.

2003;27(2):237. https://doi.org/10.2307/30036530

[22] Leonhardt D, Mandrella M, Kolbe LM. Diving into the Relationship of Information Technology and Organizational Agility: A Meta-Analysis. International Conference on Information Systems (ICIS). 2016.

[23] Teece D, Peteraf M, Leih S. Dynamic Capabilities and Organizational Agility: Risk, Uncertainty, and Strategy in the Innovation Economy. California Management Review. 2016 08;58(4):13-35. https://doi.org/10.1525/cmr.2016.58.4.13

[24] Raisch S, Birkinshaw J, Probst G, Tushman ML. Organizational Ambidexterity: Balancing Exploitation and Exploration for Sustained Performance. Organization Science. 2009 08;20(4):685-695. https://doi.org/10.1287/orsc.1090.0428 
[25] Lu, K. (Ram) Ramamurthy. Understanding the Link Between Information Technology Capability and Organizational Agility: An Empirical Examination. MIS Quarterly.

2011;35(4):931. https://doi.org/10.2307/41409967

[26] O'Reilly CA, Tushman ML. Organizational Ambidexterity: Past, Present, and Future. Academy of Management Perspectives. 2013 Nov;27(4):324-338.

https://doi.org/10.5465/amp.2013.0025

[27] Rehm S, Goel L. Using information systems to achieve complementarity in SME innovation networks. Information \& Management. 2017 06;54(4):438-451.

https://doi.org/10.1016/j.im.2016.10.003

[28] Hite JM. Evolutionary Processes and Paths of Relationally Embedded Network Ties in Emerging Entrepreneurial Firms. Entrepreneurship Theory and Practice. 2005 01;29(1):113144. https://doi.org/10.1111/j.1540-6520.2005.00072.x

[29] Smith-Doerr L, Powell W. Networks and Economic Life. In: Smelser NJ, Swedberg WW, eds. The Handbook of Economic Sociology. Princeton: Princeton University Press; 1994.

[30] Neirotti P, Raguseo E. On the contingent value of IT-based capabilities for the competitive advantage of SMEs: Mechanisms and empirical evidence. Information \& Management. 2017 03;54(2):139-153. https://doi.org/10.1016/j.im.2016.05.004

[31] Goel S, Jones RJ. Entrepreneurial Exploration and Exploitation in Family Business. Family Business Review. 201601 28;29(1):94-120.

https://doi.org/10.1177/0894486515625541

[32] Leonhardt D, Haffke I, Kranz J, Benlian A. Reinventing the it function: the role of it agility and it ambidexterity in supporting digital business transformation. European Conference on Information Systems (ECIS). 2017, 968.

[33] Lee O(, Sambamurthy V, Lim KH, Wei KK. How Does IT Ambidexterity Impact Organizational Agility?. Information Systems Research. 2015 06;26(2):398-417. https://doi.org/10.1287/isre.2015.0577

[34] Zhou J, Bi G, Liu H, Fang Y, Hua Z. Understanding employee competence, operational IS alignment, and organizational agility - An ambidexterity perspective. Information \& Management. 2018 09;55(6):695-708. https://doi.org/10.1016/j.im.2018.02.002

[35] Lubatkin MH, Simsek Z, Ling Y, Veiga JF. Ambidexterity and Performance in Small-to Medium-Sized Firms: The Pivotal Role of Top Management Team Behavioral Integration. Journal of Management. 2006 Oct;32(5):646-672.

https://doi.org/10.1177/0149206306290712

[36] Hoyer V, Stanoevska-Slabeva K. IT impacts on operation-level agility in service industries. European Conference on Information Systems. 2009, 111.

[37] Cao Q, Gedajlovic E, Zhang H. Unpacking Organizational Ambidexterity: Dimensions, Contingencies, and Synergistic Effects. Organization Science. 2009 08;20(4):781-796.

https://doi.org/10.1287/orsc.1090.0426

[38] Held H. KMU- und Start-up-Management. Kohlhammer; 2019.

[39] Venohr B, Meyer KE. The German Miracle Keeps Running: How Germany's Hidden Champions Stay Ahead in the Global Economy. SSRN Electronic Journal. 2007; https://doi.org/10.2139/ssrn.991964

[40] KFW. Mittelstand ist der Motor der deutschen Wirtschaft. www.kfw.de/KfW-Konzern/ KfW-Research/Mittelstand.html. Accessed 2020 June 10.

[41] Hofstede Insights. What about Germany?. www.hofstede-insights.com/ countrycomparison/germany. Accessed 2020 July 10. 
[42] Nemkova E. The impact of agility on the market performance of born-global firms: An exploratory study of the 'Tech City' innovation cluster. Journal of Business Research. 2017 Nov;80:257-265. https://doi.org/10.1016/j.jbusres.2017.04.017

[43] Clark D. Gross domestic product at current market prices of selected European countries in 2018. https://www.statista.com/statistics/685925/gdp-of-european-countries/. Accessed 2020 June 15.

[44] Eisenhardt KM. Building Theories from Case Study Research. Academy of Management Review. 1989 Oct;14(4):532-550. https://doi.org/10.5465/amr.1989.4308385

[45] Rubin HJ, Rubin IS. Qualitative Interviewing: The Art of Hearing Data. SAGE Publications, Inc; 2011.

[46] Gnyawali DR, Park B(. Co-opetition and Technological Innovation in Small and MediumSized Enterprises: A Multilevel Conceptual Model. Journal of Small Business Management. 2009 07;47(3):308-330. https://doi.org/10.1111/j.1540-627x.2009.00273.x

[47] Lee TW. Using qualitative methods in organizational research. Thousand Oaks, Calif.: Sage Publications; 1999.

[48] Hollensbe EC, Khazanchi S, Masterson SS. How Do I Assess If My Supervisor and Organization are Fair? Identifying The Rules Underlying Entity-Based Justice Perceptions. Academy of Management Journal. 2008 Dec;51(6):1099-1116. https://doi.org/10.5465/amj.2008.35732600

[49] Myers MD. Qualitative Research in Business and Management. 3rd edition. SAGE Publications Ltd; 2019.

[50] Locke K. Grounded Theory in Management Research. SAGE Publications Ltd; (SAGE series in Management Research) 2001.

[51] Glaser BG, Strauss AL, Strutzel E. The Discovery of Grounded Theory; Strategies for Qualitative Research. Nursing Research. 1968 07;17(4):364.

https://doi.org/10.1097/00006199-196807000-00014

[52] Warner KS, Wäger M. Building dynamic capabilities for digital transformation: An ongoing process of strategic renewal. Long Range Planning. 2019 06;52(3):326-349.

https://doi.org/10.1016/j.Irp.2018.12.001

[53] Conforto EC, Salum F, Amaral DC, da Silva SL, de Almeida LFM. Can Agile Project Management be Adopted by Industries Other than Software Development?. Project Management Journal. 2014 06;45(3):21-34. https://doi.org/10.1002/pmj.21410

[54] Arbussa A, Bikfalvi A, Marquès P. Strategic agility-driven business model renewal: the case of an SME. Management Decision. 201703 20;55(2):271-293.

http://doi.org/10.1108/md-05-2016-0355

[55] Nold H, Michel L. The performance triangle: a model for corporate agility. Leadership \& Organization Development Journal. 201605 03;37(3):341-356. https://doi.org/10.1108/lodj07-2014-0123

[56] Sharifi $\mathrm{H}$, Zhang $\mathrm{Z}$. A methodology for achieving agility in manufacturing organisations: An introduction. International Journal of Production Economics. 1999 05;62(1-2):7-22.

https://doi.org/10.1016/s0925-5273(98)00217-5 